\title{
RADIOMETRIC DATING WITH THE UNIVERSITY OF WASHINGTON TANDEM VAN DE GRAAFF ACCELERATOR*
}

G W FARWELL, T P SCHAAD, F H SCHMIDT, and M-Y B TSANG

Nuclear Physics Laboratory

and

P M GROOTES and MINZE STUIVER

Quaternary Isotope Laboratory, University of Washington,
Seattle, Washington 98195

ABSTRACT. The University of Washington Model FN tandem Van de Graaff accelerator is being used for the measurement of extremely small isotopic abundance ratios, notably ${ }^{14} \mathrm{C} /{ }^{12} \mathrm{C}$ and ${ }^{10} \mathrm{Be} /{ }^{9} \mathrm{Be}$, in a joint project of the Nuclear Physics Laboratory (NPL) and the Quaternary Isotope Laboratory (QL). The experimental arrangements and technical developments are described, and some preliminary results on isotopic ratios in carbon and beryllium are presented.

\section{INTRODUCTION}

The first efforts toward the establishment of an accelerator-based radiochronology program at the University of Washington were undertaken at the Nuclear Physics Laboratory (NPL) in June, 1977, stimulated by the publication of the paper by Muller (1977). While Muller's work was cyclotron-based, the NPL program makes use of a model FN tandem Van de Graaff accelerator. A few months later we became aware of the work of other Van de Graaff groups on ${ }^{14} \mathrm{C}$ (Bennett and others, 1977; Nelson, Korteling, and Stott, 1977) and of the pioneering work on ${ }^{10} \mathrm{Be}$ carried out at the Grenoble cyclotron (Raisbeck and others, 1978). Collaboration with the University of Washington Quaternary Isotope Laboratory (QL) began in early 1978. Our joint program benefited substantially from the First Conference on Radiocarbon Dating with Accelerators held at the University of Rochester in April of that year (Gove, 1978), at which work under way at a number of North American and European laboratories was reported.

\section{Experimental arrangements: special problems and (a few) solutions} Beam transport system

The overall ion transport system is shown in schematic fashion in figure 1. Negative ions are extracted from the ion source by a potential of $25-30 \mathrm{KV}$. The terminal of the Van de Graaff is fixed at $7.000 \pm 0.002$ MV. The final ion energies are $\sim 35 \mathrm{MeV}$ for carbon $\left(\mathrm{C}^{-} \rightarrow \mathrm{C}^{+4}\right)$, and $\sim 24 \mathrm{MeV}$ for beryllium $\left(\mathrm{Be}^{16} \mathrm{O}-\rightarrow \mathrm{Be}^{+3}\right)$.

The low energy focusing system consists of an inflection magnet and a number of electrostatic elements. The magnet selects the desired ion mass. The settings of the electrostatic elements, which are very critical, are independent of mass, but do have a small dependence on beam magnitude due to loading of the Van de Graaff accelerator electrodes.

* Work supported in part by the Graduate School Research Fund of the University of Washington, the Department of Energy, and the National Science Foundation 
Apart from this latter effect, optimization of these elements can be achieved by acceleration of an easily measured beam, eg, ${ }^{13} \mathrm{C}$. The inflection magnet is then shifted to a setting appropriate for mass 14 , and no adjustments are made for the remaining elements.

As shown in figure 1, beam currents can be measured at four positions by means of Faraday cups. The first three, low energy (LEC), high energy (HEC), and image (IMC), are controlled remotely. Each serves to facilitate beam alignment for the appropriate upstream segment, and to provide normalization of data if desired. Five beam scanners, not indicated on figure 1, also greatly facilitate proper beam alignment.

The mass resolution, as measured at the high energy cup, is approximately 25. Mass resolution following the analyzing magnet is much greater-about 360 . This is a function of image slit settings (typically $\pm 2.54 \mathrm{~mm}$ ). The image slit aperture is set as small as permitted by the terminal potential stability. Since the background of unwanted ions is proportional to the image slit width, it is desirable to set this aperture as narrow as possible.

A second carbon foil stripper $\left(S_{2}\right)$ can be inserted, if desired, just upstream from the image slits; this provides a second charge exchange which is sometimes useful in eliminating unwanted ions (see below).

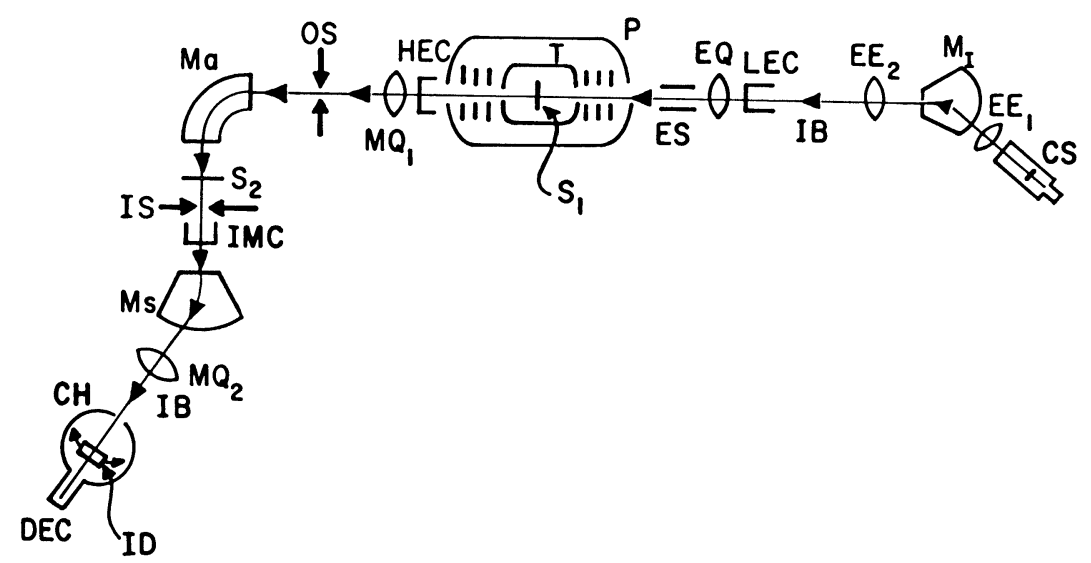
Fig 1. University of Washington tandem Van de Graaff accelerator ion transport
system for radiochronology (schematic).

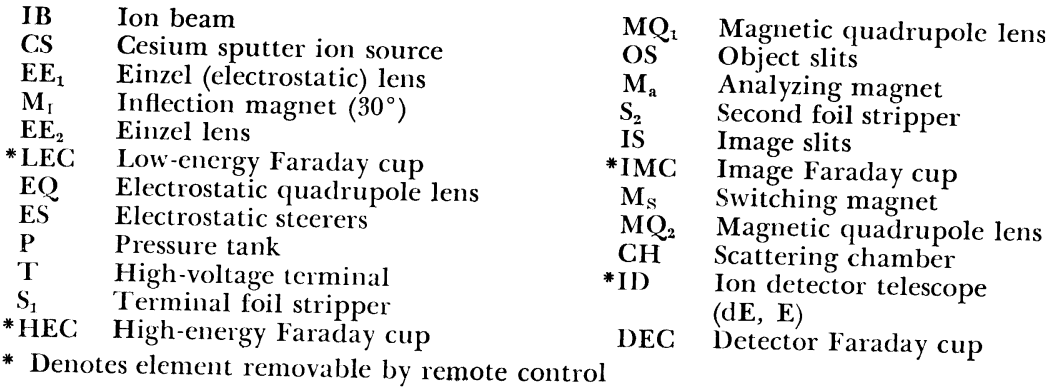


The final ion beam enters a chamber $(\mathrm{CH})$, where its magnitude can be accurately determined either by integrating the current to a large Faraday cup (DEC), or by ion counting in the detector system. The latter consists of either a single solid state surface barrier detector, or a counter telescope for simultaneous measurement of $\Delta \mathrm{E}$ in a thin detector, and $\mathrm{E}$ in a thicker detector. Particle identification and data collection are achieved by the appropriate electronics system followed by an online computer.

Unlike some other Van de Graaff beam systems, ours does not employ a velocity selector to eliminate unwanted ions (see discussion under contamination). One is planned, however.

In order to shift the whole beam system from one ion mass to another, it is necessary to alter the fields of the five magnetic elements shown in figure 1. If the system is first aligned on ${ }^{13} \mathrm{C}^{+4}$ (a measurable beam at each monitoring point), it is changed to ${ }^{14} \mathrm{C}^{+4}$ by calculating the desired magnetic settings from the observed ${ }^{13} \mathrm{C}^{+4}$ settings. The analyzing magnet is regulated by nuclear magnetic resonance (NMR); the switching magnet is current regulated, but NMR monitored. The inflection magnet is current regulated and monitored by a rotating coil magnetometer. The two quadrupoles are current regulated; it is sufficiently accurate in changing settings to assume that their fields are proportional to current. Although these quadrupoles are also biased to provide steering, the bias currents are proportional to the main current, and are, therefore, independent of ion mass.

\section{Terminal voltage regulation}

Regulation systems customarily utilize a small portion of the beam, as measured on the image slits, to control the terminal potential. However, when rare ions are accelerated the terminal must be regulated without benefit of a measurable beam. A generating voltmeter (GVM) provides a signal proportional to the terminal potential; this signal replaces the one from the slits.

Initially, the GVM signal on our accelerator lacked adequate stability; accordingly, a new type of generating voltmeter circuit was developed, based upon a principle that apparently had been overlooked (Smith, 1954; Schmidt and Fauska, 1978). The new features of the GVM system give a much-improved GVM signal with higher frequency response which controls, 1) the corona needle potential, and 2) a fastresponse correcting potential applied to the terminal stripper foil. The latter is transmitted to the terminal via a modulated light signal.

The GVM signal also is read out onto a calibrated digital voltmeter. The digital reading is compared with a selected narrow terminal voltage range. A gate signal actuates the detector output/computer input, so that ion counts are not recorded if an excursion of the terminal voltage beyond the set limits should occur. Such an excursion would reduce the transmission efficiency, or produce a burst of contaminant ions. For a typical operating situation the gate is set for $\mathrm{V}_{\mathrm{T}}=7.000 \pm 0.002 \mathrm{MV}$; 
with these settings very few excursions outside the limits of $\pm 2 \mathrm{KV}$ are observed. The limits $\pm 2 \mathrm{KV}$ are narrow enough to insure that all desired ions pass through the image slits with the settings at $\pm 2.54 \mathrm{~mm}$.

\section{Ion source}

Our ion source is a cesium sputter source manufactured by the Extrion Corporation. We have replaced the customary cone-type geometry with a new type of reflection geometry referred to as the "six-hole multiple-reflection geometry." It is shown in figure 2 (Schmidt and Farwell, 1979). Cesium ions pass through six small holes in a tantalum or molybdenum disc, and are reflected by a positively biased extraction electrode. The Cs beam impinges on a very small spot in the center of the disc where the source material is concentrated. The negative ion beam is larger than that obtained from the cone geometry, and has better emittance; thus, the number of ions transmitted through the Van de Graaff is greater.

The source button is also shown in figure 2. It consists of a smalldiameter $(2.3 \mathrm{~mm})$ short cylinder. A flange on one end serves to hold it in position sandwiched between the two molybdenum or tantalum discs. The source material consists of about $10 \mathrm{mg}$ of carbon, or 2 to $10 \mathrm{mg}$ of a metallic beryllium deposit. Typical ion yields are 5 to $20 \mu \mathrm{A}$ of ${ }^{12} \mathrm{C}^{-}$ (measured at the low-energy cup), and 10 to $40 \mathrm{nA}$ of analyzed ${ }^{9} \mathrm{Be}^{+3}$ (measured at the image cup or at the detector cup). Further details of ion source performance are given in a companion paper (Grootes and others, 1980, this volume).

\section{Contaminant ions}

Even though ions are selected by their magnetic rigidity (mass $\times$ energy $\left./(\text { charge })^{2}\right)$ by both the inflection and the analyzing magnets, large numbers of contaminant or "background" ions may arrive at the detector when the ion transport system is set for ${ }^{14} \mathrm{C}$ or ${ }^{10} \mathrm{Be}$. For ${ }^{14} \mathrm{C}$ most of the background ions are ${ }^{13} \mathrm{C}$ or ${ }^{12} \mathrm{C}$ in various charge states; with ${ }^{10} \mathrm{Be},{ }^{10} \mathrm{~B}$ is ubiquitous and abundant and in a given charge state has, unfortunately, almost exactly the same energy and magnetic rigidity as ${ }^{10} \mathrm{Be}$.

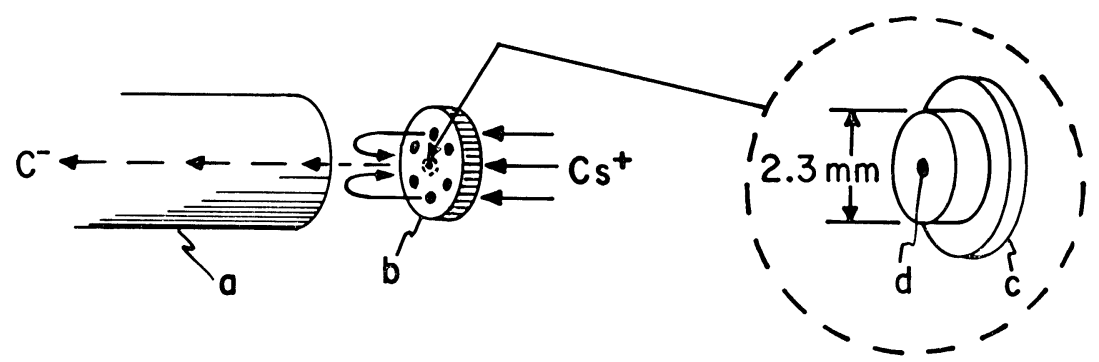

Fig 2. Cesium sputter source six-hole multiple reflection geometry and carbon source button (Schmidt and Farwell, 1979).

a Biased extraction electrode (reflects $\mathrm{Cs}^{+}$ions, accelerates $\mathrm{C}^{-}$- ions)

b Source button assembly (carbon button supported by tantalum discs)

c Carbon button (5-10mg)

d Focal spot for incident $\mathrm{Cs}^{+}$ions and emitted $\mathrm{C}^{-}$ions (less than $1 \mathrm{~mm}$ in diameter) 
The problem is well-known, and experiments at other laboratories have shown that the addition of a velocity selector (crossed electric and magnetic fields), or an electric field deflection alone, serves to eliminate most of these contaminants.

We have not yet constructed such a selector; rather, we have studied the origin of some of the contaminating ions with the objective of finding other means of eliminating them, at least sufficiently for some applications.

Carbon-Figure 3 shows an energy spectrum of ions observed in a solid-state detector with the system tuned to ${ }^{14} \mathrm{C}$. The source was graphite prepared from an unknown sample of hardwood (see below). The ${ }^{12} \mathrm{C}^{-}$ beam emerging from the ion source was about $2.5 \mu \mathrm{A}$. The count rate for ${ }^{14} \mathrm{C}$ was 100 per minute, while the total count rate, including all the contaminating peaks, was $\sim 1900$ per minute - a very modest rate easily handled by the electronics and computer. The only peak which signifcantly interferes with the ${ }^{14} \mathrm{C}$ is the ${ }^{13} \mathrm{C}^{+4}$. As shown on figure 3 , the energy separation of these for this particular measurement is excellent; with the additional requirement of a correct $\Delta \mathrm{E}$ for ${ }^{14} \mathrm{C}$, the separation is still better.

The spectrum shown in figure 3 is a particularly good one, partly due to very low hydrogen content of the source material resulting from the "graphitization" step in source preparation. Without this step (heating to $\sim 2500^{\circ} \mathrm{C}$ ), the relative intensities of carbon contamination peaks are from two to four orders of magnitude larger, while the ${ }^{12} \mathrm{C}-$ beam from the ion source is from 5 to 10 times smaller. Further details of the source preparation procedures are discussed in a companion paper (Grootes and others, 1980).
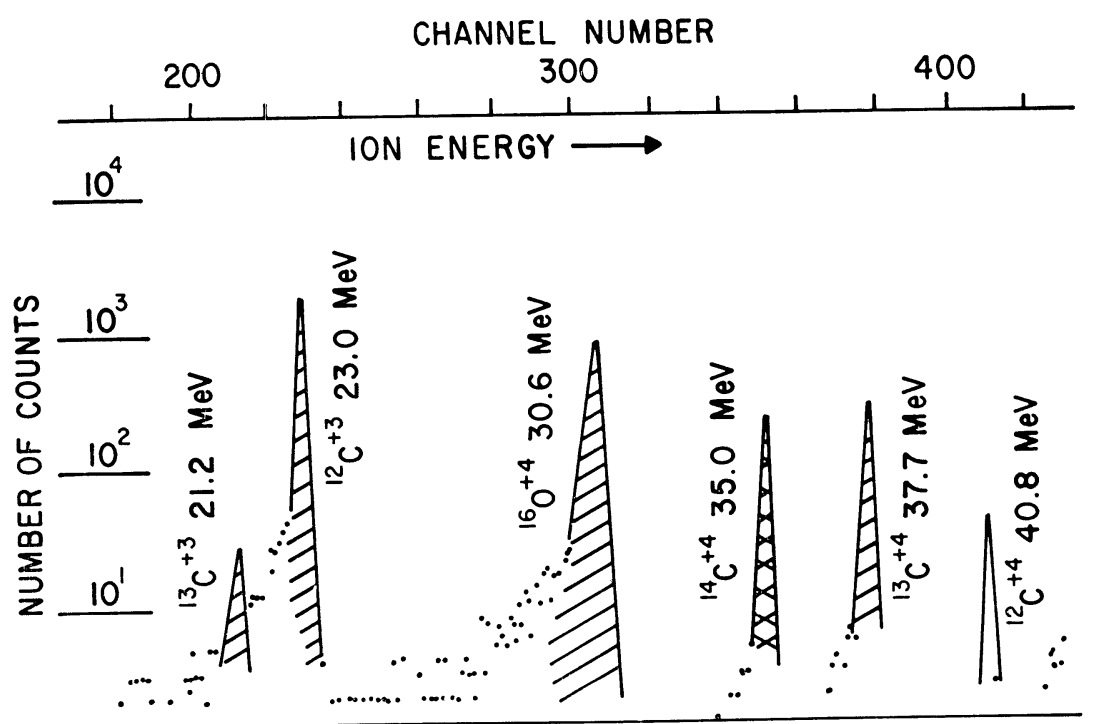

Fig 3. Energy spectrum for ${ }^{14} \mathrm{C}^{+4}$ and contaminant ions from a graphitized contemporary wood source (logarithmic intensity scale). 
The contaminant ions are produced, in most cases, by a second charge exchange process in the high energy, or second stage, acceleration tube of the tandem Van de Graaff. The primary sources of contamination are $\left({ }^{13} \mathrm{CH}\right)^{-}$and $\left({ }^{12} \mathrm{CH}_{2}\right)^{-}$molecular ions. These are stripped at the carbon foil stripper at the terminal, and then undergo a second exchange in residual gas at just the correct position in the high energy tube to acquire the correct energy and charge for the magnetic rigidity setting of the analyzing magnet. For example, the ${ }^{13} \mathrm{C}^{+4}$ is produced by $\left({ }^{13} \mathrm{CH}\right)^{-} \rightarrow$ ${ }^{13} \mathrm{C}^{+5} \rightarrow{ }^{13} \mathrm{C}^{+4}$, where the +5 to +4 exchange takes place 45 percent of the way down the high energy tube. The choice of 7.00 MV terminal potential and charge state +4 for the ${ }^{14} \mathrm{C}$ serves to avoid a charge exchange of the ${ }^{13} \mathrm{C}$ at the midsection of the high energy tube, where we have observed a sixfold increase in the ${ }^{13} \mathrm{C}^{+4}$ peak, in agreement with the experience of others (eg, Middleton, 1978).

Thus, in addition to the use of a velocity selector or other ion filter, there are two measures which will reduce or eliminate the contaminating ions: an improved vacuum in the high energy tube section, and reduction of the hydrogen content of the carbon source material. We have taken steps in both these directions. Additionally, new accelerating tubes were installed in early 1979, accompanied by greatly improved operational stability and reduced background. The improved stability enabled us to reduce the image slit width, a measure which also reduces background.

Figure 4 shows a comparison of segments of $\mathrm{E}$ versus $\mathrm{dE}$ displays for runs on two sources: a) 1964 charcoal, which has been graphitized, and b) "Xl wood" (unknown age) converted to $\mathrm{CO}_{2}$, "cracked" from $\mathrm{CO}$ to $\mathrm{C}$, and molded and graphitized (Grootes and others, 1980). The separation between the ${ }^{13} \mathrm{C}^{+4}$ and ${ }^{14} \mathrm{C}^{+4}$ is good in both cases. However, the magnitude of the ${ }^{13} \mathrm{C}^{+4}$ peak relative to the ${ }^{14} \mathrm{C}^{+4}$ is smaller by a factor of about five for the Xl wood; in addition, the ${ }^{14} \mathrm{C}$ content of the Xl is about onehalf that of the 1964 charcoal. Thus, the Xl sample is about 10 times freer of contamination. XI is our "cleanest" sample in this regard, to date, and the process by which it was made is especially promising since $\mathrm{CO}_{2}$ is the usual product of the processing of carbonaceous samples from nature.

Two additional observations are of interest. First, the quality of a carbon source can easily be determined in advance of the final detector system, because the magnitude of the mass 13 beam relative to the mass 14 beam can be measured in the high energy Faraday cup (HEC). A ratio of 1000 or greater indicates a "good" source. Second, the quality of a source is greatly degraded if the ion source is let up to air after operation. We have shown that imbedded cesium evidently adsorbs water vapor which cannot be efficiently removed by subsequent Cs ion bombardment. A corollary observation is that ion source sparking, if it occurs on the epoxy insulator surfaces of the Extrion-type source, produces a destructive hydrogen contamination.

Beryllium-The best ion yields have been achieved by the process $\left({ }^{10} \mathrm{Be}^{16} \mathrm{O}\right)^{-} \rightarrow{ }^{10} \mathrm{Be}^{+3}$ with the molecular dissociation and Be ion stripping 
occurring in the terminal stripper $S_{1}$ (fig 1 ). We use Be metal sources in the presence of $\mathrm{O}_{2}$ (about $2.5 \times 10^{-6}$ torr); further details are given in Grootes and others (1980).

These sources produce essentially only ${ }^{10} \mathrm{~B}$ as background. We elimi. nate the ${ }^{10} \mathrm{~B}$ entirely by use of a relatively thick second stripper $\mathrm{S}_{2}$ (fig 1 ) of carbon (about $\left.\mathrm{lmg} / \mathrm{cm}^{2}\right)$. The overall process is then $\left({ }^{10} \mathrm{Be}^{16} \mathrm{O}\right)^{-} \rightarrow$ ${ }^{10} \mathrm{Be}^{+3}\left(\right.$ at $\left.\mathrm{S}_{1}\right) \rightarrow{ }^{10} \mathrm{Be}^{+4}\left(\right.$ at $\left.\mathrm{S}_{2}\right) .{ }^{10} \mathrm{~B}$ ions undergo the same processes but are eliminated by the switching magnet: ${ }^{10} \mathrm{~B}^{+4}$ ions emerging from $\mathrm{S}_{2}$ have lost more energy in $\mathrm{S}_{2}$ than the ${ }^{10} \mathrm{Be}^{+4}$ ions, and emerging ${ }^{10} \mathrm{~B}^{+5}$ ions have an even more greatly reduced magnetic rigidity. The resultant ion spectrum is very clean, with virtually only ${ }^{10} \mathrm{Be}^{+4}$ present.

\section{Beryllium source materials}

We have prepared Be sources from commercial Be metal; from ${ }^{10} \mathrm{Be}-$ enriched material (metal targets with long deuteron exposure in our cyclotron); from calibrated (ie, $\beta$-counted) enriched Be; and also from ocean sediment. Some sources have been immediately available as $\mathrm{Be}$ metal; others have been made from a beryllium oxide and magnesium mixture through heating of the mixture and reduction of the $\mathrm{BeO}$, followed by evaporation of the beryllium onto an ion source button (Grootes and others, 1980).

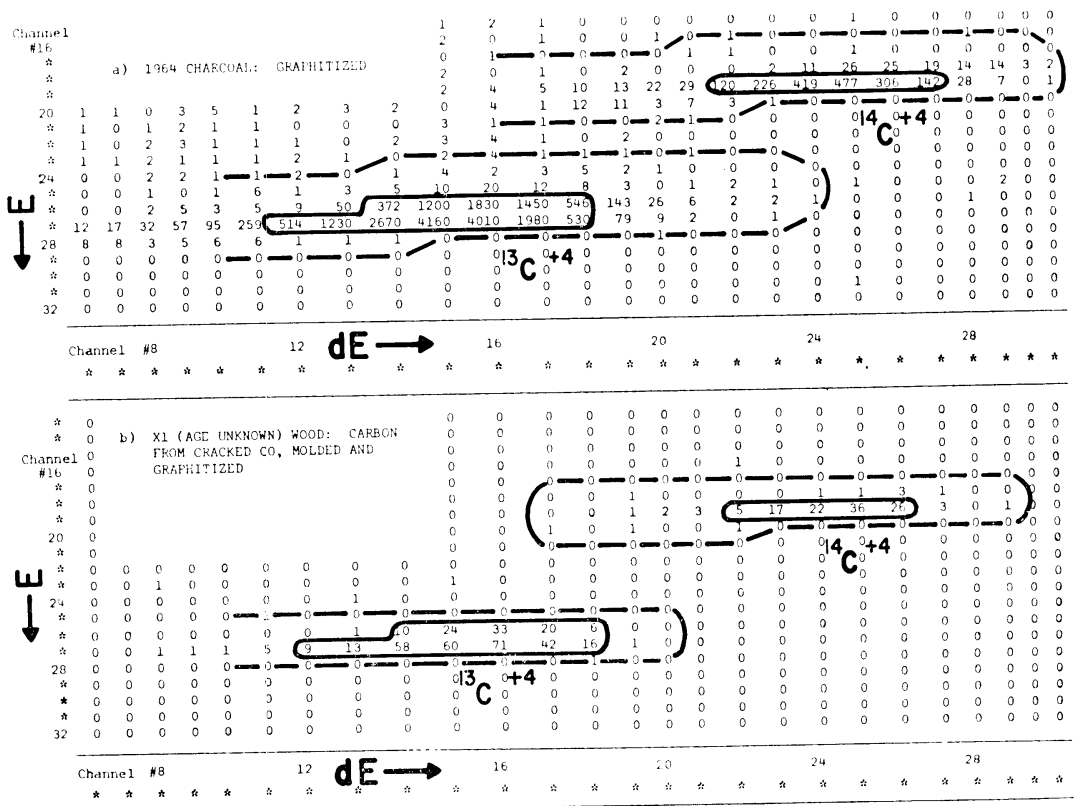

Fig 4. Two-dimensional (dE, E) printouts of spectra from two carbon sources: a) 1964 charcoal, graphitized, and b) Xl wood (cracked carbon source), graphitized. The contours outline the ${ }^{14} \mathrm{C}^{+4}$ and the ${ }^{13} \mathrm{C}^{+4}$ (contaminant) peaks. The cracked carbon source is much freer of hydrogen and the relative magnitude of its ${ }^{13} \mathrm{C}^{+4}$ peak is much smaller. Scparation of the peaks is adequate in both cases for a good ${ }^{14} \mathrm{C}$ count. 


\section{Beam normalization}

Ideally, it should be simple to measure absolute isotopic ratios accurately by comparing the counting rate of ${ }^{14} \mathrm{C}$ (or $\left.{ }^{10} \mathrm{Be}\right)$ ions at the detector to the corresponding ${ }^{13} \mathrm{C}$ or ${ }^{12} \mathrm{C}$ (or ${ }^{9} \mathrm{Be}$ ) ion beam current to a Faraday cup at essentially the same location. In practice, this is very difficult to achieve. Short- and long-term machine instabilities may cause fluctuations in ion production and transmission during the course of a comparison of ion counts and beam currents; isotopic fractionation may occur at the ion source; and other factors may also give rise to errors. Therefore, each of our absolute ratio determinations has been based upon a comparison of the (apparent) isotopic ratio for an unknown sample with that for a known standard (eg, wood from dated tree rings or $\beta$-counted beryllium).

In making such comparisons, the best method is to alternate the standard and unknown sources rapidly over many cycles. While simple in principle, this is difficult to execute because of mechanical problems of switching sources, and because at each alternation one must measure the corresponding ${ }^{12} \mathrm{C}$ or ${ }^{13} \mathrm{C}$ (or ${ }^{9} \mathrm{Be}$ ) beam for normalization purposes.

For carbon comparisons, we cycle only the inflection system and normalize to the ${ }^{12} \mathrm{C}-$ beam at the low-energy cup. The remainder of the beam transport system is optimized at the outset for ${ }^{13} \mathrm{C}\left({ }^{13} \mathrm{C}-\rightarrow{ }^{13} \mathrm{C}+{ }^{4}\right)$ and then shifted permanently to the corresponding ${ }^{14} \mathrm{C}$ set of parameters. With a standard source in place, the inflection magnet is set for mass 12 and the ${ }^{12} \mathrm{C}$ - beam to the low-energy cup is integrated for a short time. We then shift the inflection magnet to mass 14 and record detector pulses in the computer for one or two minutes. We shift back to mass 12 to remeasure the low-energy ${ }^{12} \mathrm{C}-$ current, then shift to the (unknown) second source and repeat the entire procedure. This comparison cycle is repeated 5 to 10 times. We are working toward automization of this entire procedure.

Normalization for the beryllium is more difficult because the $\mathrm{BeO}$ low-energy beam is not a reliable indicator of source output. Therefore, we measure the analyzed ${ }^{9} \mathrm{Be}^{+3}$ beam to the image cup (IMC) or to the detector cup (DEC) (fig I). Thus, changing from ${ }^{9} \mathrm{Be}$ to ${ }^{10} \mathrm{Be}$ requires that we shift not only the inflection magnet but also the analyzing magnet (or both analyzing and switching magnets) and the associated magnetic quadrupoles. While this scheme is entirely feasible, the shifts require time (up to several minutes) and make it difficult to alternate sources rapidly.

Additional comments on these methods of normalization will be made below following presentation of our results to date.

\section{RESULTS}

\section{Carbon}

Our results, preliminary in character, are presented in tables 1 and 2 . Table 1 gives the ${ }^{14} \mathrm{C}$ count rates, normalized to the ${ }^{12} \mathrm{C}-$ low-energy ion beam, for 1964 wood (several samples); 1939 wood (2 samples); Ernst wood (a hardwood of unknown age and origin, 2 samples); 2 archaeologic sam- 
ples from an eastern Washington site (thought to be 3000 to 5000 years old, based on archaeologic evidence); and X1 wood (age unknown to the accelerator experimenters). The times available for measurement were limited by other demands on the accelerator, and we feel that the degree of internal consistency is reasonable considering the uncertainties associated with normalization to the ${ }^{12} \mathrm{C}-$ beam.

Also shown in table 1 are rough numbers for graphite and for graphite and coal-tar pitch (see also Grootes and others, 1980). The observed results for graphite may indicate a small but real ${ }^{14} \mathrm{C}$ content in graphite, may imply an equivalent "age background" for our accelerator system of 40,000 years or so, or may have been the consequence of cross-contamination of the graphite from other sources during the run. Further measurements are planned.

Data taken directly from intercomparisons of pairs of samples are given in table 2. Counting times were limited (especially for the archaeologic sample where failure of the ion source interfered) and the data are sparse, but the results are not unsatisfactory for this stage in the development of our facility.

\section{Beryllium}

${ }^{10} \mathrm{Be} /{ }^{9} \mathrm{Be}$ ratios from three accelerator runs made at intervals of several weeks are given in table 3 . These are absolute ratios made by reference to a $\beta$-counted primary standard $(\mathrm{Be} \# \mathrm{~L})$ and a secondary standard $(\mathrm{Be} \# \mathrm{~A})$ which was calibrated against Be \#L in the run of August 10. As

TABLE 1

Carbon results: ${ }^{14} \mathrm{C}$ counting rates

\begin{tabular}{|c|c|c|c|}
\hline Sample & \multirow{2}{*}{$\frac{{ }^{14} \mathrm{C} \text { counts }}{3382}$} & \multirow{2}{*}{$\begin{array}{c}\text { Time }(\mathrm{min}) \\
21.6\end{array}$} & \multirow{2}{*}{$\frac{{ }^{14} \mathrm{C} \text { counts } / \mathrm{min} / \mu \mathrm{A}^{12} \mathrm{C}^{-}}{40.5 \pm 6.5^{*}}$} \\
\hline 1964 wood \# & & & \\
\hline \# & 3284 & 34.2 & $34.8 \pm 5.2 *$ \\
\hline \# & 13,606 & 70.5 & $43.6 \pm 3.3^{*}$ \\
\hline$\#$ & 11,997 & 52.3 & $43.7 \pm 4.7 *$ \\
\hline$\#$ & 6214 & 16.9 & $54.6 \pm 1.2 *$ \\
\hline \multirow{2}{*}{1939 wood } & 10,574 & 41.0 & $25.4 \pm 3.4 *$ \\
\hline & 9773 & 69.6 & $28.2 \pm 0.8 *$ \\
\hline Ernst wood \# & 1221 & 22.2 & $15.2 \pm 1.0 *$ \\
\hline$\#$ & 2360 & 60.2 & $13.2 \pm 0.8^{*}$ \\
\hline \multicolumn{4}{|l|}{ Archaeologic } \\
\hline sample** \# & 538 & 19.3 & $14.9 \pm 0.2$ \\
\hline$\#$ & 833 & 28.8 & $10.1 \pm 1.4$ \\
\hline Xl wood $\dagger$ & 1290 & 50.5 & $25.5 \pm 2.4 *$ \\
\hline Graphite $\ddagger$ & $<10$ & 9.7 & $<0.3$ \\
\hline Graphite and & 43 & 31.3 & $0.19 \pm 0.08$ \\
\hline pitch & 12 & 9.8 & $0.37 \pm 0.10$ \\
\hline
\end{tabular}

* $\sigma$ based on scatter of individual $10 \mathrm{~min}$ measurements of the same sample; counting statistics contribute negligibly to observed scatter.

** Charred wood from an archaeologic site in eastern Washington; probably 3000 to 5000 years old, based on archaeologic evidence.

†X1 was made from "cracked" carbon with pitch. Part of the cracked carbon $(5 \mathrm{mg})$ was combusted. It gave $\delta^{13}{ }_{\mathrm{PDB}} \mathrm{C}=-25.24 \pm 0.11 \%$.

† Combustion and mass spectrometric analysis gave $\delta^{13}{ }_{\mathrm{PDB}} \mathrm{C}=-24.99 \pm 0.10 \%$.

Ditto $\delta^{13}{ }_{\mathrm{PDB}} \mathrm{C}=-26.10 \pm 0.09 \%$. 
explained above, rapid alternation of sources is not feasible when normalization is made to the analyzed ${ }^{9} \mathrm{Be}^{+3}$ beam at the image cup (July 10 and August 10 runs) or the detector cup (June 20 run). However, the consistency of the results for the individual samples that were measured on both June 20 and July 10 is encouraging.

To our knowledge, the ${ }^{10} \mathrm{Be} /{ }^{9} \mathrm{Be}$ measurement on an ocean sediment sample (Be \#P) is the first to be reported using the accelerator method, and the ratio found is consistent with the usual range of values determined by $\beta$-counting. We plan to do further work in this field.

\section{Comparison of carbon and beryllium results: normalization}

Despite the difficulty of adjusting all of the magnetic parameters of the beam transport system, a comparison of the ${ }^{10} \mathrm{Be} /{ }^{9} \mathrm{Be}$ and ${ }^{14} \mathrm{C} /{ }^{12} \mathrm{C}$ results indicates that, so far, the normalization procedure used with Be is preferable. Specifically, the average, over all samples, of the individual $\sigma$ 's derived from the scatter of several measurements on a given sample is 3.6 \pm 0.5 percent for ${ }^{10} \mathrm{Be} /{ }^{9} \mathrm{Be}$ with normalization to the ${ }^{9} \mathrm{Be}+3$ beam at the image cup, while that for ${ }^{14} \mathrm{C} /{ }^{12} \mathrm{C}$ is $8.7 \pm 1.5$ percent for normalization to the ${ }^{12} \mathrm{C}$ - beam at the low-energy cup. Thus, there might appear to be significant uncertainties affecting the ratio of ${ }^{14} \mathrm{C}^{+4}$, as measured at the detector, to ${ }^{12} \mathrm{C}^{-}$, as measured before high-voltage acceleration. However, the run during which some of the carbon data for the comparison method were collected was seriously flawed by an earlier ion source failure which resulted in excessive hydrogen contamination of all samples. It is possible, of course, to normalize to ${ }^{13} \mathrm{C}^{+4}$ at the image cup or detector cup, as with beryllium; because of accelerator loading effects, however, direct normalization to ${ }^{12} \mathrm{C}^{+4}$ is difficult or impossible without drastic attenuation of ${ }^{12} \mathrm{C}$ prior to high-voltage acceleration.

\section{Extension of the technical dating range for carbon: ${ }^{14} \mathrm{C} /{ }^{12} \mathrm{C}$ enrichment}

By a combination of thermal diffusion enrichment and accelerator technology, we are working toward an extension of the technical dating range well beyond the 75,000 years so far achieved with $\beta$-counting techniques. Details of the present enrichment capability, and some suggestions, are given in Grootes and others (1980).

TABLE 2

Carbon results: intercomparisons of ${ }^{14} \mathrm{C} /{ }^{12} \mathrm{C}$ ratios

\begin{tabular}{lccr}
\hline \multicolumn{1}{c}{ Samples compared } & $\begin{array}{c}\text { Ratio of }{ }^{14} \mathrm{C} /{ }^{12} \mathrm{C} \\
\text { isotopic ratios }\end{array}$ & $\begin{array}{c}\text { Expected } \\
\text { ratio }\end{array}$ & $\begin{array}{c}\text { Time } \\
(\text { min) }\end{array}$ \\
\hline 1939 wood/1964 wood & $0.56 \pm 0.03$ & $0.56 *$ & 90 \\
X1 wood/1964 wood & $0.56 \pm 0.11$ & $0.48 * *$ & 38 \\
Archaeologic sample/1964 wood & $0.38 \pm 0.22$ & 0.39 to 0.30 & 19 \\
Ernst wood/1964 wood & $0.34 \pm 0.05$ & Unknown & 40 \\
\hline
\end{tabular}

* There is some uncertainty here because, 1) the ${ }^{14} \mathrm{C}$ content of the atmospheric $\mathrm{CO}_{2}$ during the growing season will have varied considerably and the average value at the sample location is unknown, and, 2) no pretreatment to eliminate lignin deposited during hardwood formation (around 1973) was used.

** Datum provided by Minze Stuiver. 
TABle 3

${ }^{10} \mathrm{Be} /{ }^{9} \mathrm{Be}$ ratios from several Van de Graaff accelerator runs

\begin{tabular}{|c|c|c|c|c|c|}
\hline & & & \multicolumn{3}{|c|}{${ }^{10} \mathrm{Be} /{ }^{9} \mathrm{Be}$ ratio } \\
\hline \multicolumn{2}{|c|}{ Source } & & 10 Aug $79 *,+$ & 10 July $79 * *,+$ & 20 June $79 \dagger, \ddagger$ \\
\hline $\mathrm{Be}$ & $\# 4$ & $\begin{array}{l}\text { Deuteron-irradiated } \\
\text { metal fragment }\end{array}$ & & $\begin{array}{r}8.44 \pm 0.15 \\
\times 10 \rightarrow\end{array}$ & $\begin{array}{r}9.69 \pm 0.51 \\
\times 10^{-}\end{array}$ \\
\hline $\mathrm{Be}$ & $\# \mathrm{~A}$ & $\begin{array}{l}\text { Deuteron-irradiated } \\
\text { metal fragment }\end{array}$ & $\begin{array}{l}1.19 \pm 0.03 \\
\times 10^{-} \\
\text {(Normalized } \\
\text { to Be } \# \mathrm{~L})\end{array}$ & $\begin{array}{l}1.19 \times 10^{-6} \\
(\text { Secondary } \\
\text { standard })\end{array}$ & $\begin{array}{l}1.19 \times 10^{-} \\
(\text {Secondary } \\
\text { standard) }\end{array}$ \\
\hline $\mathrm{Be}$ & $\# \mathbf{F}$ & $\begin{array}{l}\text { Deuteron-irradiated metal } \\
\text { from BeO reduction/ } \\
\text { evaporation }\end{array}$ & & $\begin{array}{r}7.14 \pm 0.20 \\
\times 10^{-7}\end{array}$ & $\begin{array}{r}7.28 \pm 0.21 \\
\times 10^{-7}\end{array}$ \\
\hline $\mathrm{Be}$ & $\# G$ & $\begin{array}{l}\text { Deuteron-irradiated metal } \\
\text { from BeO reduction/ } \\
\text { evaporation }\end{array}$ & & $\begin{array}{r}1.77 \pm 0.07 \\
\times 10^{-7}\end{array}$ & $\begin{array}{r}1.69 \pm 0.08 \\
\times 10^{-7}\end{array}$ \\
\hline $\mathrm{Be}$ & $\# \mathrm{P}$ & $\begin{array}{l}\text { Ocean sediment: metal } \\
\text { from BeO reduction/ } \\
\text { evaporation }\end{array}$ & & & $\begin{array}{r}3.02 \pm 0.72 \\
\times 10^{\rightarrow}\end{array}$ \\
\hline $\mathrm{Be}$ & $\# M$ & $\begin{array}{l}\text { Commercial metal, } \\
\text { not irradiated }\end{array}$ & & $<2 \times 10^{-12}$ & \\
\hline $\mathrm{Be}$ & \#L & $\begin{array}{l}\text { Metal from reduction/ } \\
\text { evaporation of } \beta \text {-counted } \\
\text { BeO standard } \Phi\end{array}$ & $\begin{array}{l}1.79 \times 10^{-0} \\
\text { (Primary } \\
\text { standard) }\end{array}$ & & \\
\hline
\end{tabular}

* Nornalization by measurenent of ${ }^{\circ} \mathrm{Be}$ ion currents to image Faraday cup IMC (fig 1); absolute ${ }^{10} \mathrm{Be} /{ }^{9} \mathrm{Be}$ ratio by reference to $\mathrm{Be} \# \mathrm{~L}$ (primary standard).

** Normalization as in *; absolute ${ }^{10} \mathrm{Be} /{ }^{9} \mathrm{Be}$ ratios by reference to $\mathrm{Be} \# \mathrm{~A}$ (secondary standard).

+ Normalization by measurement of ${ }^{9} \mathrm{Be}^{+4}$ currents to detector Faraday cup DEC (fig 1); absolute ${ }^{10} \mathrm{Be} /{ }^{9} \mathrm{Be}$ ratios as in **.

$\ddagger \sigma$ based on scatter of individual measurements on the same sample; counting statistics contribute negligibly in most cases.

The $\beta$-counted material from which this source was prepared was kindly provided by $\mathrm{J} R$ Arnold and his associates at the University of California, San Diego.

\section{ACKNOWLEDGMENTS}

It is a pleasure to acknowledge the special support and technical assistance of William G Weitkamp, Technical Director, and Harold Fauska, Assistant Technical Director, of the Nuclear Physics Laboratory. Many other members of the NPL, too numerous to mention by name, also contributed to our work. We are grateful to J R Arnold, of the University of California, San Diego, for providing us with $\beta$-counted BeO material.

\section{REFERENCES}

Bennett, C L, Beukens, R P, Clover, M R, Gove, H E, Liebert, R B, Litherland, A E, Purser, K H, and Sondheim, W E, 1977, Radiocarbon dating using electrostatic accelerators: negative ions provide the key: Science, v 198, p 508-510.

Fauska, H and Schmidt, F H, 1978, Improvement of the generating voltmeter: Univ Washington, Nuclear Physics Lab, Ann Rept, p 119-123.

Gove, H E, ed, 1978, Conference on radiocarbon dating with accelerators, 1st, Proc: Rochester, N Y, Univ Rochester.

Grootes, P M, Stuiver, Minze, Farwell, G W, Schaad, T P, and Schmidt, F H, 1980, Enrichment of ${ }^{14} \mathrm{C}$ and sample preparation for $\beta$-decay and ion counting, in Stuiver, Minze and Kra, Rence, eds, Internatl radiocarbon conf, 10th, Proc: Radiocarbon, v 22, no. 2, p 487-500. 
Middleton, R, 1978, Some remarks on negative ion sources and ${ }^{14} \mathrm{C}$ dating, in Gove, H E, ed, Conference on radiocarbon dating with accelerators, 1st, Proc: Rochester, N Y, Univ Rochester, p 196-219.

Muller, R A, 1977, Radioisotope dating with a cyclotron: Science, v 196, p 489-494.

Nelson, D E, Korteling, R G, and Stott, W R, 1977, Carbon-14: direct detection at natural concentrations: Science, v 198, p 507-508.

Raisbeck, G M, Yiou, F, Fruneau, M, and Loiseaux, J M, 1978, Beryllium-10 mass spectrometry with a cyclotron: Science, v 202, p 215-217.

Schmidt, F H and Farwell, G W, 1979, An effective reflection-type geometry for sputter ion sources: Am Phys Soc Bull, v 24, p 650.

Schmidt, F H and Fauska, H, 1978, Van de Graaff control without image slits: Am Phys Soc Bull, v 23, p 542.

Smith, L G, 1954, Electric field meter with extended frequency range: Rev Sci Instruments, v 25, p 510-513.

\section{DISCUSSION}

Currie: How was the carbon sample gas cracked?

Grootes: The sample was introduced into the cracking system as $\mathrm{CO}_{2}$. It was circulated continuously by convection over $\mathrm{Zn}$ powder on glass wool at $\cong 400^{\circ} \mathrm{C}$. After $\approx \mathrm{l} / 2$ hour the gas had been converted completely to CO. Then the DC glow discharge was started and maintained until the system pressure had dropped from the original 20 torr to about $200 \mu$. 